\title{
The role of expectations for liking and other positive Affiliative outcomes in the get-acquainted process that occurs over Computer-mediated video communication
}

\author{
Susan Sprecher ${ }^{1}$ (D) \\ Accepted: 2 February 2021 / Published online: 23 February 2021 \\ (C) The Author(s), under exclusive licence to Springer Science+Business Media, LLC part of Springer Nature 2021
}

\begin{abstract}
People often develop expectations prior to meeting someone for the first time. These pre-interaction expectations, which include how much they will like the other and how much they will enjoy the interaction, have likely increased because of information easily obtained about others through social media. What is not well understood is whether these expectations prior to a first meeting are associated with interpersonal evaluations formed during the get-acquainted interaction. In this study, pre-interaction expectations were collected from both members of 71 dyads. Then, after the dyads interacted through a structured self-disclosure task conducted over Skype, their reactions were assessed again. Several findings of the study have implications for people meeting for the first time, including over visual forms of computer-mediated communication (CMC). Findings included that pre-interaction expectations were associated with reactions after the interaction, a visual greeting with another before learning information about the other did not moderate the effect of that information on liking and other affiliative outcomes, and participants underestimated how much they were liked after the interaction. The implications of the findings are important because people are increasingly becoming acquainted through visual forms of CMC, which has been amplified during the COVID-19 pandemic.
\end{abstract}

Keywords Expectations · Liking - Acquaintance · Fast friends - Self-disclosure - Computer-mediated communication · Video-mediated communication · Getting-acquainted interactions

"You can make more friends in two months by becoming interested in other people than you can in two years by trying to get other people interested in you" (Dale Carnegie, 1936, p. 58)

As indicated by the above quote from a best-selling advice book, the key to a person's development of social bonds lies within his or her own attitudes and behaviors. If a person expects (prior to an initial interaction) to like the other, that expectation likely influences the person's behaviors directed toward the other, interpretations of the other's behaviors, and reactions during the interaction - which in turn likely influence the other's behaviors, interpretations, and reactions.

Susan Sprecher

sprecher@ilstu.edu

1 Illinois State University, Normal, IL, USA
Although pre-interaction expectations of liking and other forecasts may be the critical factors that set into motion what actually occurs in a get-acquainted interaction, preinteraction expectations have rarely been considered in research. One reason is the methodological challenge of obtaining data from both members of getting-acquainted pairs of strangers, both before they have a first interaction and again after the interaction. In the current research, however, data from a social interaction study were analyzed to examine how participants' expectations of liking a stranger (about whom they had limited information) were associated with their post-interaction liking and other judgments of the interaction. In addition, the study examines how two manipulated variables (whether the dyad received bogus similarity or dissimilarity information prior to the interaction and whether the dyad had a visual greeting prior to receiving this information) affected the pre-interaction expectations.

Understanding the development of social bonds is exceedingly important. The role of friends and intimate relationships for people's health and well-being has been firmly established (Holt-Lunstad, 2018). People's daily lives, however, also 
include interactions with many non-close others, including strangers being met for the first (and possibly only) time. Some of these first interactions may develop into acquaintanceships or relationships. However, even if there is no further contact, such interactions can help meet people's need for belongingness (Baumeister \& Leary, 1995; Hirsch \& Clark, 2019; Sandstrom \& Dunn, 2014). Furthermore, feeling affection, closeness, and a sense of rapport with others in such brief interactions can enhance well-being more than having uncomfortable, awkward, and negative interactions (Vittengl \& Holt, 2000).

Because communication technologies have increased in the past decade, opportunities for interactions between strangers and the development of peripheral ties are unprecedented (Bayer, Triệu, \& Ellison, 2020; Ellison \& Vitak, 2015). In addition, opportunities for pre-interaction expectations have increased because of information that can be easily obtained through social media, communication technologies, and online dating profiles (Bayer et al., 2020; LeFebvre, 2018; Sharabi, 2020). Therefore, it is important to extend knowledge of how pre-interaction expectations contribute to positive (or negative) outcomes in initial interactions including those that occur over computer mediated communication (CMC). There are various topics in the literature on the social psychology of attraction that provide insight about the influence of preinteraction expectations developed at the zero-acquaintance stage on later outcomes after the initial interaction. These topics are summarized next.

\section{The Self-Fulfilling Prophecy of Expecting to Be Liked}

Although the primary focus of this study is on people's expectations of their own liking for a stranger whom they are about to meet, a related expectation is how much people expect to be liked by the other. The self-fulfilling prophecy of liking (also called the acceptance prophecy) refers to how anticipatory acceptance (liking) from another can create the anticipated reaction - acceptance from the other. For example, a person who expects to be liked by a stranger will likely engage in certain behaviors (e.g., smiling, self-disclosure) that then elicit liking from the other (Montoya, Kershaw, \& Prosser, 2018; Snyder, Tanke, \& Berscheid, 1977; Stinson, Cameron, Wood, Gaucher, \& Holmes, 2009). The other side of this phenomenon is the self-fulling prophecy of rejection if a person believes that they will be disliked by another, they likely behave in ways that elicit such a negative reaction. The finding that the expectation of being liked (or disliked) by another leads to corresponding reactions has been supported in research. For example, in an often-cited experimental study, Curtis and Miller (1986) arranged for participants to believe that they were either liked or disliked by an interaction partner.
Those who believed they were liked engaged in more positive behaviors (e.g., more self-disclosure) and expressed more liking for the other than those who believed they were disliked.

\section{The Reciprocity of Liking Effect}

One of the reasons that the self-fulfilling prophecy of liking operates is due to the reciprocity of liking principle, which was first discussed in the context of a norm of reciprocity (Gouldner, 1960) and has been identified as a major predictor of attraction (e.g., Berscheid \& Reis, 1998; Eastwick \& Finkel, 2009; Montoya \& Horton, 2012). If people believe that they are liked by another - or even just expect prior to an interaction that they will be liked - they tend to like in return. For example, in experimental studies, people who learn that they are liked by another person (usually through bogus information) express more liking and other affiliative behaviors toward the other than those who learn they are disliked or those who have no information on how the other evaluates them (Aronson \& Worchel, 1966; Montoya \& Insko, 2008; Zimmermann, Schindler, Klaus, \& Leising, 2018). In addition, survey research that has asked participants why they became attracted to a friend or romantic partner has shown that a reason frequently offered is the other's liking (Aron, Dutton, Aron, \& Iverson, 1989; Sprecher, 1998). The belief that another likes us is gratifying and rewarding because it validates that we are desirable and have likeable qualities (Eastwick \& Finkel, 2009). This belief is also associated with the perception that the other is trustworthy and will act benevolently towards us (Montoya \& Insko, 2008).

The reciprocity principle and the evidence supporting it suggests that the cause-effect relationship is the perception of being liked leads to liking the other. However, prior to or co-occurring with this mutual and reciprocal liking is the expectation of liking the other. That is, one's own pre-interaction expectation of liking the other can contribute to the perception of being liked by the other, i.e., reciprocal liking. Relatedly, the expectation of liking the other can lead to the projection of one's own positive feelings to the other. This projection can contribute to the other actually experiencing liking, as mediated by one's own warm behaviors (Lemay Jr \& Wolf, 2016). Interestingly, though, recent research has identified a liking gap in which people underestimate how much they are liked by a stranger (a conversation partner in a lab setting) (Boothby, Cooney, Sandstrom, \& Clark, 2018).

\section{The Similarity Effect and Expectations of Liking}

Matching the reciprocity effect in being identified as a major predictor of liking in initial interactions is the similarity effect 
(e.g., Finkel \& Eastwick, 2015). Greater similarity - both perceived and actual (i.e., the degree to which two people are objectively similar, as assessed by standardized measures or by bogus similarity information) and across several dimensions (e.g., attitudes, traits, leisure interests) - is associated with greater liking for the other (Byrne, 1971; Montoya, Horton, \& Kirchner, 2008). There are various explanations for the similarity effect, and these explanations and the mediating variables that represent these explanations, continue to be debated today (Hampton, Fisher Boyd, \& Sprecher, 2019; Montoya et al., 2008; Montoya \& Horton, 2012, 2013). Some of the explanations for the similarity effect refer to expectations of liking the other as well as the perception of being liked by the other (Aronson \& Worchel, 1966; Condon \& Crano, 1988). For example, if people acquire information about a stranger that suggests that the stranger is similar to them, they are likely to expect to like the other, to enjoy the interaction, and to be liked in return.

More generally, learning that another is similar can lead to the forecast of future rewards, which also contributes to the expectation of liking the other. For example, according to two theories on initial interactions - Social Penetration Theory (Altman \& Taylor, 1973) and Predicted Outcome Value Theory (Sunnafrank, 1986) - information learned about another (e.g., similarity) can lead to liking because of a rewards/ cost analysis in which the person forecasts or predicts what the other will be like. If people expect a positive interaction when they meet - based on initial information learned including through CMC communication, social media, or online dating profiles - their liking for the other will likely be enhanced.

\section{Other Pre-Interaction Expectations}

Attraction researchers have examined other types of expectations that can occur prior to a first interaction and that may influence liking and other reactions to that first interaction. As one example, research has shown that the expectation of having a future interaction with a stranger enhances the expectation of liking the other (Berscheid, Graziano, Monson, \& Dermer, 1976; Darley \& Berscheid, 1967; Tyler \& Sears, 1977), including when the interaction is expected to occur over CMC (Ramirez Jr., 2007). It has been suggested that the expectation of future interactions leads to perceived outcome dependency and the perception of the self and other as a unit, which can lead to greater attention and attraction to the other (Berscheid et al., 1976; Darley \& Berscheid, 1967).

Although the effect of pre-interaction expectations of liking on post-interaction reactions has not been the focus of prior research, there are a few other studies with relevant data. In the creation of a closeness-generating procedure, Aron, Melinat, Aron, Vallone, and Bator (1997) included in one of their studies a manipulation of expectation of mutual liking prior to the stranger-stranger dyads having an interaction. Some of the dyads were told: "We have taken great care in matching partners. Based on our experience in previous research we expect that you and your partner will like one another - that is, you have been matched with someone we expect you will like and who will like you." (p. 367). The other dyads were given alternative directions that did not include the expectation of liking the other. No difference was found between the conditions in either closeness or liking and Aron et al. speculated that the closeness task was so engaging that it may have made the initial expectation of liking less relevant.

On the other hand, a very recent study suggests that expectations and reactions based on pre-interaction information received can be associated with later outcomes after an interaction. Sharabi (2020) conducted an experiment in which the members of some cross-sex dyads who arrived for an experimental session for a simulated first date first viewed an online dating profile created by the other dyad member, whereas other dyads did not have this pre-interaction viewing. A predate assessment of eagerness to communicate with the other was associated positively with the degree to which they were satisfied with the communication and desired to have future interaction assessed later after the brief unstructured interaction.

\section{A Negative Consequence of Exceptionally High Pre-Interaction Expectations}

Although pre-interaction expectations of liking and other positive outcomes (e.g., enjoying the interaction) should create self-fulfilling prophecies and be associated with positive post-interaction outcomes, there can also be negative consequences of high pre-interaction expectations. For example, according to the hyperpersonal theory (Walther, 1992, 1996), idealized partner expectations can form initially in $\mathrm{CMC}$, but high expectations may not be met once there is a subsequent face-to-face $(\mathrm{FtF})$ interaction, and as a result disappointment can occur (e.g., Antheunis, Schouten, Valkenburg, \& Peter, 2012). Although the hyperpersonal theory was developed to apply specifically to expectations that develop over text-based CMC, such idealized expectations can occur based on other pre-interaction information, including what is gained through a brief video-CMC greeting or information about the degree to which the other is similar (such as what might be gleaned from a dating profile or a post in social media). Sharabi and Caughlin (2017) conducted a unique longitudinal study of online daters and found a decrease in their attraction from before to after their first $\mathrm{FtF}$ meeting. The researchers argued that a disillusionment model that is traditionally applied to the newlywed period (e.g., Huston, Caughlin, Houts, Smith, \& George, 2001) can also apply to transitions such as moving from a pre-interaction 
judgment period to the first $\mathrm{FtF}$ encounter. When expectations are too high, they cannot be sustained when one encounters reality, and thus there can be a decrease in attraction.

\section{Purposes to this Study}

In sum, pre-interaction expectations have not been systematically studied for their implications for affiliative outcomes experienced after an initial interaction. However, people gain information about others before there is interaction, and especially through the affordances provided by social media and other communication technologies. Pre-interaction information is likely to influence expectations of liking for the other which in turn should influence post-interaction assessments. Past research that has examined initial expectations has often not involved an actual follow-up interaction or data collected after the interaction (Eastwick, Finkel, \& Simpson, 2019).

In this study, data were analyzed from a social interaction study that involved pre-interaction measures of expectations of liking (and of enjoying the interaction) and then subsequent measures of reactions after the CMC-visual interaction. Two contextual variables prior to interaction were manipulated: (1) whether the members of the dyad had an initial videomediated greeting (before receiving any additional information); and (2) whether the information received about the other before the interaction was (bogus) similarity or dissimilarity information. These manipulations have implications for relationship and friendship formation that often occurs over the Internet. People often learn about the traits and interests of a potential friend or romantic partner through social media or online profiles, which can lead to inferences about the similarity of the other. In addition, some people may have a visual greeting before learning any significant information about each other, and this greeting can impact the effect of the information learned prior to the interaction.

Thus, the first purpose of this study was to examine the effects of information learned about another on expectations formed prior to the interaction. A research question is posed about the effects of an initial prior greeting (due to the lack of prior research on this topic), and a research hypothesis is posed about the effects of similarity.

$R Q 1$ : Will the pairs who have a video-mediated greeting expect to enjoy the interaction and like each other more than do those who do not have such a greeting?

H1: Those who receive (bogus) similarity information will expect to enjoy the interaction and like the other more than those who receive (bogus) dissimilarity information.

The second and primary purpose of the study was to examine how pre-interaction expectations influence later reactions after there is interaction. That is, will expectations of enjoying the interaction and liking the other prior to the interaction create a reality of affectionate interaction, as suggested by the quote from Dale Carnegie (1936)? In considering post-interaction reactions, it will be first examined whether the pre-interaction manipulations considered in this study have effects on post-interaction reactions. Then, the major hypothesis is a prediction of associations between preinteraction expectations and post-interaction reactions.

RQ2: Will the pre-interaction manipulations (e.g., similarity information) have effects on post-interaction liking and other reactions?

H2: Pre-interaction expectations for liking will be associated positively with: (a) own liking (and the other affective reactions) experienced for the other after the interaction; and (b) actual liking expressed by the partner after the interaction.

\section{Method}

\section{Participants}

The participants were 142 undergraduate students ${ }^{1}$ from a U.S. Midwestern University. (This sample was after eliminating one pair because they reported being acquainted.) Most of the students were from a psychology participant pool, although a smaller proportion were volunteers from a sociology class who elected to use this research opportunity as a way to earn extra credit (among other options). Pairs of participants were scheduled at the same time, based on their availability and that of the student experimenters. If both participants did not arrive during their scheduled time, the one who did arrive was assigned another research activity. Data collection occurred over three semesters in order to obtain what was determined to be an adequate sample size.

Due to the gender imbalance of the participant pool (and the larger university), a large majority $(n=109 ; 76.9 \%)$ were women. The mean age of the participants was $19.82(S D=$ 2.88). A majority (68.3\%) of the participants identified themselves as White; $9.9 \%$ were Black, $10.6 \%$ were Hispanic/ Latino, and $4.2 \%$ were Asian (a few did not provide their race or indicated mixed race). Of the 71 dyads, 39 were femalefemale, 28 were male-female, one was male-male, and 3 had an unknown sex composition because one member had not responded to the gender question.

\footnotetext{
${ }^{1}$ In three dyads, one member was not able to complete the post-interaction survey (e.g., the session started late, and the student needed to go to class). They will be included in the analyses only for the pre-interaction rating data, but not for post-interaction rating data.
} 


\section{The Pre-Interaction Procedure}

Participants who signed up for the study were scheduled in pairs (based on availability) for the experimental session. The participants in each pair arrived to different rooms in a university building and were greeted by their own experimenter, who provided directions to the study. Then, the experimenters arranged for some of the dyads, randomly determined, to greet each other over Skype (video). All participants then responded to a rating form that included several dichotomous items requesting self-descriptive information such as traits, preferences, and interests (this information was used for the manipulation of similarity). After responding to the form, the participants completed an online survey that included background questions (gender, age, race, etc.) and two questions that assessed their expectations for the upcoming interaction. Then, the participants received the rating sheet ostensibly completed by their interaction partner (located in another room) but, in fact, was filled in by the experimenter (for a similar method, see Sprecher, 2019). After viewing the bogus rating sheet (which was manipulated to be similar or dissimilar to their own answers), the participants completed a brief online survey that asked their expectations for the interaction (including a question on expectations for liking).

\section{The Interaction Procedure}

After the above preliminary steps, the pairs engaged in a 15min getting-acquainted interaction. The dyad members were in two different rooms, and the interaction occurred over video-mediated communication (Skype). They engaged in a structured self-disclosure task, which consisted of a combination of items from Aron et al.'s (1997) Closeness-Generating Inventory and Sedikides, Campbell, Reeder, and Elliot's (1999) Relationship Closeness Induction Task. The questions in the self-disclosure task were presented in three sets (of 5 min each), with each set increasing in intimacy. The question list was presented to each member of the pair, and the dyad members were directed to take turns being the first to ask a question. More specifically, they were told that one of them would ask a question, the other would disclose, and then the other would ask the same question of the first. The experimenters entered the rooms to indicate when their participants should go on to the next set of questions. When the session ended, the experimenters had their participant complete a final online reaction.

\section{The Self-Descriptive Rating Form and the Similarity/Dissimilarity Manipulation}

The self-descriptive form included 17 items that asked the participants to describe themselves, followed with dichotomous responses. Some of the items began with "Which do you prefer?" (e.g., reality show vs. sitcom; coffee vs. tea; big party vs. romantic dinner for 2). Other items began, "Which best describes you?" (e.g., introvert vs. extrovert; sloppy vs. neat freak). After the participant completed the form, the experimenter picked it up and explained that they would return with the other participant's completed form. The two experimenters met in the hallway and fabricated a new form for each of the dyad members. Depending on the condition to which their participant was randomly assigned, the experimenters prepared each bogus version so that the pair had 3 of the 17 items similar or dissimilar. Which items were selected for the similar responses (in the dissimilarity condition) and for the dissimilar responses (in the similarity condition) were randomly determined.

\section{Measures of Dependent Variables}

\section{Expectations Prior to Receiving Bogus Information (and Also Prior to the Interaction)}

At the end of the initial online survey, two items asked the participants about their expectations for the upcoming interaction. One question asked how eager they were to interact with the other and the other question asked about expectations for enjoying the interaction. Each question was followed by a 1 (not at all) to 7 (a great deal) response scale.

\section{Expectations after Receiving Bogus Information (but Prior to the Interaction)}

Participants completed a second (brief) online survey after they received the bogus information about the other. The participants were asked a second time how eager they were to interact with the other and the degree to which they thought they would enjoy the interaction. They were also asked how much they expected that they would like the other ("How much do you think you will like the other person?"). Each question was followed by a 1 (not at all) to 7 (a great deal) response scale. Participants were also asked two questions about their perception of similarity with the other person: "How much do you think you have in common with the other person?" $(1=$ nothing or almost nothing, $7=$ a great deal $)$ and "How similar do you think you and the Other are likely to be?" $(1=$ not at all, $7=$ a great deal $)$. A composite was created based on the mean of the two similarity items, which had a Cronbach's alpha of 88 .

\section{Liking and Other Affiliative Outcomes after the Interaction}

After the interaction, the participants completed an online survey that included several measures of reactions to the partner and to the interaction. 
Liking Liking was assessed with three items. One item was: "How much did you like the other?" $(1=$ not at all, $7=$ a great deal). The other two items were adapted from Byrne's (1971) Interpersonal Judgment Scale. The first Byrne item asked about general feelings $(1=I$ feel that $I$ would probably like this person very much; to $7=I$ feel that I would probably dislike this person very much). The second Byrne item asked participants about their desire to work with the person again in an experiment $(1=I$ believe that I would very much dislike working with this person in an experiment, $7=I$ believe that $I$ would very much enjoy working with this person in an experiment). The composite score for liking was based on the mean of the three liking items, after the first Byrne item was recoded. Cronbach's alpha for a composite score was .78.

Perceptions of being liked Participants were asked, "How much do you think the Other liked you?" $(1=$ Not at all; to $7=$ A great deal).

Closeness Closeness to the other was assessed with two items. First, a general question on closeness was asked: "How close do you feel toward the Other?" $(1=$ Not at all, $7=$ A great deal). In addition, participants responded to the Inclusion of Other in the Self (IOS) Venn diagram (Aron, Aron, \& Smollan, 1992). This is a simple, validated, and commonly used measure to assess closeness, and required the participants to select the pair of circles (which overlapped to almost no degree to overlapping almost completely) that best represented their interaction (for examples of use, see Aron et al., 1992; Fraley \& Aron, 2004). Because the Cronbach's alpha for the 2 -item closeness index was low (.55) the two items are analyzed separately.

Enjoyment of interaction Enjoyment of interaction was assessed with three items: (1) "How much did you enjoy the interaction?" (2) "How much did you and the other laugh during the interaction?;" and (3) "How much fun was the interaction?" Each item was followed by a 7-point response scale with the anchors, $1=$ not at all, $4=$ somewhat; to $7=a$ great deal. The composite score was represented by the mean of the three items, and Cronbach's alpha for the composite score was .80 .

Perceived responsiveness of the other Participants were presented with four items that assessed the degree to which they perceived their partner to be responsive in the situation. Three of the items were from Reis, Maniaci, Caprariello, Eastwick, and Finkel's (2011) Responsiveness scale and were: "The Other seemed to really listen to me," "The Other seemed interested in what I am thinking and feeling," and "The Other was "on the same wavelength" with me." A fourth item was written by the author and has been used in prior social interaction studies (Sprecher \& Treger, 2015), and was the item,
"The other was responsive to my questions/answers." Each item was followed by a 7-point response scale, with options anchored in the following ways: $1=$ Not at all true in this situation; $4=$ Somewhat true in this situation; and $7=$ Very true in this situation. The mean of the items represented the composite score of the four items, and Cronbach's alpha was .92.

Desire for further interaction Desire for more interaction was assessed with two similarly worded questions (that appeared in different sections of the post-interaction survey): "How much do you wish you could have more interaction in the future?" and "How much would you like to spend time with the Other again in the future?" The response options ranged from $1=$ not at all; to $7=a$ great deal. The mean of the two items represented a total composite score and had a Cronbach's alpha of 86 .

Perceived similarity Perceived similarity was assessed with the same two items used in the pre-interaction survey. The mean of the items represented the total composite, and Cronbach's alpha was .91.

\section{Results}

\section{Overview to the Analyses}

First, intraclass correlations were calculated for the dyad members' scores on the expectation measures. The correlations were non-significant for all of the expectation measures, and ranged from -.13 to .05 . Not surprising, however, the intraclass correlation was significant for the manipulation check of perceived similarity $(.76, p=.001)$, as both members of the dyads had received the same bogus information (either similarity or dissimilarity). Because the intraclass correlations were nonsignificant for the measures of expectations, the analyses were conducted at the individual level. The dyadic nonindependence in similarity was handled by controlling for the similarity manipulation in the analyses that examined the associations of participants' own expectations with their partner's reactions.

\section{Pre-Interaction Expectations before Receipt of the Bogus Similarity/Dissimilarity Information}

Participants scored in the moderate range on the two expectations questions that appeared at the end of the preliminary online survey that was administered before the bogus similarity information was shared. On average, participants were somewhat eager to interact with the stranger $(M=3.90$, $S D=1.24)$ and also believed they would enjoy the interaction a moderate amount $(M=4.26, S D=1.06)$. 
To address $R Q 1$, participants who had a skype greeting with their interaction partner $(n=56)$ were compared with the participants who did not have a skype greeting $(n=86)$, on the two expectation items. The second group consisted of both participants who were randomly assigned to the noSkype greeting group $(n=74)$ and participants who were assigned to the Skype greeting but the technology did not work $(n=12)$. Participants who engaged in the Skype greeting reported being more eager to interact $(M=4.16, S D=1.24)$ than participants who did not have the Skype greeting $(M=$ $3.73, S D=1.21 ; t[138]=2.05, p=.04 ; d=.35$ ). However, there was not a significant difference in expectations of enjoying the interaction as a function of having a Skype greeting $(M=4.44, S D=.92)$ versus not having one $(M=4.14$, $S D=1.13), t[138]=1.63, p=.106, d=.29$ ).

\section{Pre-Interaction Expectations after Receipt of the Bogus Similarity/Dissimilarity Information}

As noted earlier, after the participants received the information ostensibly completed by their interaction partner (who was presented to be similar or dissimilar to them), they completed a second online survey. This online survey asked them once again how eager they were to interact with the other and how much they thought they would enjoy the interaction. It also asked how much they thought they would like the other person, how similar they thought they would be to the other, and how much they believed they had in common (as noted earlier, the last two items were combined into a similarity index). As shown in the first column of Table 1, the participants scored at the midpoint or higher on the expectation items and perceived similarity.

To examine whether participants' expectations depended on whether the bogus information they received presented the other to be similar or dissimilar and whether there was an initial video greeting, a 2 (similarity vs. dissimilarity information) $\times 2$ (skype greeting vs. no skype greeting) ANOVA was conducted on the pre-interaction reactions. As the results show in Table 1, the main effect for the similarity manipulation was significant for most of the pre-interaction expectation variables. Participants in the similarity condition, relative to the participants in the dissimilarity condition, expected to like the other more, expected to enjoy the interaction more, and not surprisingly, perceived greater similarity, in support of $H 1$. In addition, there was a near-significant difference in eagerness to interact (greater in the similarity condition than in the dissimilarity condition).

However, the skype greeting manipulation (which occurred prior to receiving the bogus similarity/dissimilarity information) did not have an effect on the reactions assessed after receiving the bogus information. In addition, the similarity $\mathrm{x}$ skype greeting interaction was not significant for any of the variables, which indicates that the effect of the similarity information on pre-interaction expectations did not vary as a function of whether the two had "met" each other briefly over Skype before receiving the similarity/dissimilarity information.

\section{Post-Interaction Ratings as a Function of the Initial Skype Greeting and the Bogus Information on Similarity/Dissimilarity}

$R Q 2$ asked whether there continued to be any effects of the pre-interaction manipulations on reactions experienced after the interaction. These results are presented in Table 2.

The pre-interaction similarity manipulation continued to have a strong effect on perceived similarity after the interaction. Relative to the dyads who received pre-interaction bogus dissimilarity information, the dyads who received preinteraction bogus similarity information perceived greater

Table 1 Pre-Interaction Expectations After Receiving Bogus Information as a Function of the Similarity Condition and Skype Greeting

\begin{tabular}{|c|c|c|c|c|c|c|c|c|}
\hline & $\begin{array}{l}\text { Total } \\
\text { Sample }(N= \\
142) M(S D)\end{array}$ & $\begin{array}{l}\text { Similarity } \\
\text { condition }(n= \\
\text { 66) } M(S D)\end{array}$ & $\begin{array}{l}\text { Dissimilarity } \\
\text { condition }(n= \\
\text { 76) } M(S D)\end{array}$ & $\begin{array}{l}\text { Main effect for } \\
\text { similarity } \\
\text { information } F(\& \\
\left.\eta_{\mathrm{p}}{ }^{2}\right)\end{array}$ & $\begin{array}{l}\text { Initial Greet } \\
\text { Over Skype }(n= \\
\text { 56) } M(S D)\end{array}$ & $\begin{array}{l}\text { No Greet over } \\
\text { Skype }(n=86) \\
M(S D)\end{array}$ & $\begin{array}{l}\text { Main effect for } \\
\text { Skype greeting } \\
F\left(\& \eta_{\mathrm{p}}{ }^{2}\right)\end{array}$ & $\begin{array}{l}\text { Interaction } \\
F\left(\& \eta p^{2}\right)\end{array}$ \\
\hline $\begin{array}{l}\text { How eager to } \\
\text { interact }\end{array}$ & $4.22(1.27)$ & $4.45(1.29)$ & $4.01(1.22)$ & $3.77(.027)$ & $4.25(1.13)$ & $4.20(1.36)$ & $.39(.003)$ & $.47(.003)$ \\
\hline $\begin{array}{l}\text { Expectations } \\
\text { for liking }\end{array}$ & $4.54(.98)$ & $4.86(.99)$ & $4.24(.87)$ & $14.72^{* * * *}(.098)$ & $4.52(.85)$ & $4.55(1.06)$ & $.59(.004)$ & $.01(.000)$ \\
\hline $\begin{array}{l}\text { Expect to } \\
\text { enjoy the } \\
\text { interaction }\end{array}$ & $4.34(1.10)$ & $4.71(1.15)$ & $4.00(.94)$ & $15.87^{* * * *}(.104)$ & $4.32(.94)$ & $4.35(1.20)$ & $.76(.006)$ & $.00(.000)$ \\
\hline $\begin{array}{l}\text { Perceived } \\
\text { similarity }\end{array}$ & $3.90(1.65)$ & $5.39(.79)$ & $2.57(.91)$ & $320.04^{* * * *}(.702)$ & 3.49 (1.47) & $4.17(1.71)$ & $.02(.000)$ & $2.53(.018)$ \\
\hline
\end{tabular}


Table 2 Post-Interaction Reactions as a Function of Pre-interaction Manipulations of Similarity Information and Skype Greeting

\begin{tabular}{|c|c|c|c|c|c|c|c|c|}
\hline & $\begin{array}{l}\text { Total } \\
\text { Sample }(N= \\
142) M \\
(S D)\end{array}$ & $\begin{array}{l}\text { Similarity } \\
\text { condition }(n= \\
66) M(S D)\end{array}$ & $\begin{array}{l}\text { Dissimilarity } \\
\text { condition }(n= \\
\text { 76) } M(S D)\end{array}$ & $\begin{array}{l}\text { Main effect for } \\
\text { similarity } \\
\text { information } F(\& \\
\left.\eta_{\mathrm{p}}^{2}\right)\end{array}$ & $\begin{array}{l}\text { Initial Greet } \\
\text { Over Skype }(n= \\
\text { 56) } M(S D)\end{array}$ & $\begin{array}{l}\text { No Greet over } \\
\text { Skype }(n=86) \\
M(S D)\end{array}$ & $\begin{array}{l}\text { Main effect for } \\
\text { Skype greeting } \\
F\left(\& \eta_{\mathrm{p}}{ }^{2}\right)\end{array}$ & $\begin{array}{l}\text { Interaction } \\
F\end{array}$ \\
\hline $\begin{array}{l}\text { Liking for the } \\
\text { Other }\end{array}$ & $5.72(.76)$ & $5.84(.74)$ & $5.62(.78)$ & $1.99(.015)$ & $5.58(.67)$ & $5.83(.81)$ & $1.80(.013)$ & .85 \\
\hline $\begin{array}{l}\text { Perception of } \\
\text { being Liked }\end{array}$ & $4.74(1.03)$ & $4.92(1.06)$ & $4.57(.99)$ & $1.42(.011)$ & $4.43(.99)$ & $4.96(1.01)$ & $6.70^{*}(.048)$ & .03 \\
\hline $\begin{array}{l}\text { Closeness } \\
\text { (IOS) }\end{array}$ & $4.43(1.48)$ & $4.52(1.49)$ & $4.34(1.47)$ & $.26(.002)$ & $4.30(1.48)$ & $4.51(1.48)$ & $.36(.003)$ & .06 \\
\hline $\begin{array}{l}\text { Closeness } \\
\quad \text { (subjective) }\end{array}$ & $3.79(1.26)$ & $3.82(1.40)$ & $3.77(1.12)$ & $.16(.001)$ & $3.61(1.17)$ & $3.93(1.31)$ & $2.47(.018)$ & .98 \\
\hline $\begin{array}{c}\text { Enjoyment of } \\
\text { Interaction }\end{array}$ & $5.56(.98)$ & $5.66(.91)$ & $5.46(1.03)$ & $.58(.004)$ & $5.44(1.01)$ & $5.63(.95)$ & $.83(.006)$ & .33 \\
\hline $\begin{array}{l}\text { Desire for } \\
\text { Future } \\
\text { Interaction }\end{array}$ & $4.42(1.26)$ & $4.63(1.23)$ & $4.23(1.26)$ & $2.78(.021)$ & $4.26(1.23)$ & $4.54(1.27)$ & $.50(.004)$ & .36 \\
\hline $\begin{array}{l}\text { Perceived } \\
\text { Similarity }\end{array}$ & $4.79(1.21)$ & $5.19(1.19)$ & $4.42(1.12)$ & $11.01^{* *}(.077)$ & $4.50(1.06)$ & $5.00(1.28)$ & $2.00(.015)$ & .13 \\
\hline $\begin{array}{l}\text { Perceived } \\
\text { Responsive- } \\
\text { ness }\end{array}$ & $5.73(1.07)$ & $5.89(1.00)$ & $5.57(1.10)$ & $.65(.005)$ & $5.45(.97)$ & $5.92(1.07)$ & $5.73^{*}(.042)$ & .85 \\
\hline
\end{tabular}

$* p<.05, * * p<.01, * * * p<.001$

similarity after the interaction. This occurred even though the 15-min self-disclosure interaction allowed new information about each other to be shared. Otherwise, the pre-interaction similarity manipulation did not have a significant effect on liking and the other affiliative outcomes assessed after the interaction.

The skype greeting manipulation that occurred before any bogus information on similarity was shared (and before the interaction) had a significant effect on two dependent variables measured post-interaction, but opposite to what one might expect - a higher score was found in the group with no Skype greeting for both the perception of being liked by the partner and perceived responsiveness in conversational partner. The interaction of the two manipulation variables was not significant for any of the dependent variables (that is, whether there was a Skype greeting did not moderate the effect of the similarity manipulation on post-interaction ratings).

\section{Associations of Participants' Pre-Interaction Expectations with their Own Post-Interaction Ratings}

Table 3 presents the correlations of the participants' preinteraction expectation variables with their postinteraction reactions. As these results show, the more that the participants expected (before the interaction) that they would enjoy the interaction and like the other, the more positive were their actual, later reactions $(H 2 a)$. These associations were found for both the expectations measured before receiving the bogus information and the expectations measured after the receipt of the bogus information. Thus, positive expectations (of liking the other and enjoying the interaction) before entering an interaction are associated with actually experiencing these outcomes once there is interaction. In addition, the more that the participants perceived similarity prior to the interaction, the more they perceived similarity after the interaction.

\section{Associations of Participants' Pre-Interaction Expectations with their Partner's Post-Interaction Reactions}

Next, it was considered whether the participants' preinteraction expectations were associated with their partner's reactions to them after the interaction. In these analyses, the similarity condition was controlled in order to consider nonindependence in the dyadic data (i.e., both members of a dyad experienced the same bogus information condition).

As the results in Table 4 show, generally there were no significant associations between participants' pre-interaction expectations and how their partner reacted to them after the interaction (no support for $H 2 b$ ). The one exception was a positive correlation between the participants' expectations of enjoying the interaction (measured prior to the receipt of the bogus information) and their partner's rating of enjoyment/fun in the interaction. 
Table 3 Associations of Participants' Pre-Interaction Expectations with Their Own Post-Interaction Reactions

Participants' Own Ratings after the Interaction

\begin{tabular}{|c|c|c|c|c|c|c|c|}
\hline $\begin{array}{l}\text { Liking the } \\
\text { other }\end{array}$ & $\begin{array}{l}\text { Perception of } \\
\text { being liked }\end{array}$ & $\begin{array}{l}\text { Closeness } \\
(\mathrm{IOS})\end{array}$ & $\begin{array}{l}\text { Closeness } \\
\text { (Subjective) }\end{array}$ & $\begin{array}{l}\text { Enjoyment/ } \\
\text { Fun }\end{array}$ & $\begin{array}{l}\text { Desire for future } \\
\text { interaction }\end{array}$ & $\begin{array}{l}\text { Perceived } \\
\text { similarity }\end{array}$ & $\begin{array}{l}\text { Other } \\
\text { responsiveness }\end{array}$ \\
\hline
\end{tabular}

\begin{tabular}{|c|c|c|c|c|c|c|c|c|}
\hline \multicolumn{9}{|c|}{ Ratings Before Receiving Bogus Information and Before Interaction } \\
\hline How eager to interact & .16 & .13 & .15 & $.25^{* *}$ & $.36^{* * * *}$ & $.27^{* *}$ & $.20^{*}$ & .13 \\
\hline $\begin{array}{l}\text { Expectation to enjoy } \\
\text { the interaction }\end{array}$ & $.33^{* * * *}$ & $.20^{*}$ & $.21^{*}$ & $.21^{*}$ & $.41^{* * * *}$ & $.33^{* * * *}$ & $.30^{* * * *}$ & $.26^{* *}$ \\
\hline \multicolumn{9}{|c|}{ Ratings After Bogus Information and Before Interaction } \\
\hline How eager to interact & $.30^{* * *}$ & $.26^{* *}$ & $.24^{* *}$ & $.26^{* *}$ & $.41^{* * * *}$ & $.38^{* * *}$ & $.31^{* * *}$ & $.26^{* *}$ \\
\hline $\begin{array}{l}\text { Expectation to enjoy } \\
\text { the interaction }\end{array}$ & $.26^{* *}$ & $.25^{* *}$ & .15 & $.23^{* *}$ & $.30^{* * *}$ & $.38^{* * * *}$ & $.27^{* *}$ & .16 \\
\hline $\begin{array}{l}\text { Expectation of liking } \\
\text { for the other }\end{array}$ & $.26^{* *}$ & $.34^{* * * *}$ & .14 & $.18^{*}$ & $.20^{*}$ & $.34^{* * * *}$ & $.24^{* * *}$ & .16 \\
\hline Perceived similarity & $.20^{*}$ & $.30^{* *}$ & $.18^{*}$ & .16 & $.22^{* *}$ & $.26^{* *}$ & $.41^{* * *}$ & $.22^{*}$ \\
\hline
\end{tabular}

${ }^{*} p<.05,{ }^{* *} p<.01,{ }^{* * *} p<.001$

\section{Additional Results}

The data collected could also address other issues about expectations of liking referred to in the literature review above. Results for these issues are presented below.

The liking gap Do people underestimate how much they are liked, as found by Boothby et al. (2018)? To examine this, the participants' responses to the question, "How much do you think the other liked you?" were compared with their partner's responses to the question, "How much did you like the other?"
Both items had a 7-point response scale that ranged from $1=$ not at all; to $7=$ a great deal. Support was found for the liking gap. Participants believed that they were liked less $(M=4.75$, $S D=1.05)$ than their conversational partner actually reported liking them $(M=5.42, S D=1.04)$, paired $t[130]=5.60$, $p<.001$.

Reciprocity in liking Both perceived and actual reciprocity in liking could be examined with the data collected after the interaction. First, there was evidence for actual reciprocity in liking. Controlling for the similarity condition, one partner's

Table 4 Associations of Participants' Pre-Interaction Expectations with Their Partner's Post-Interaction Reactions (controlling for Dyad Condition for Similarity)

Partner's reactions after the interaction:

\begin{tabular}{|c|c|c|c|c|c|c|c|}
\hline $\begin{array}{l}\text { Liking the } \\
\text { other }\end{array}$ & $\begin{array}{l}\text { Perception of } \\
\text { being liked }\end{array}$ & $\begin{array}{l}\text { Closeness } \\
\text { (IOS) }\end{array}$ & $\begin{array}{l}\text { Closeness } \\
\text { (Subjective) }\end{array}$ & $\begin{array}{l}\text { Enjoyment/ } \\
\text { Fun }\end{array}$ & $\begin{array}{l}\text { Desire for future } \\
\text { interaction }\end{array}$ & $\begin{array}{l}\text { Perceived } \\
\text { similarity }\end{array}$ & $\begin{array}{l}\text { Other } \\
\text { responsiveness }\end{array}$ \\
\hline
\end{tabular}

Participant's expectation scores pre-interaction:

Ratings Before Receiving Bogus Information and Before Interaction

$\begin{array}{lllllllll}\text { How eager to interact } & .03 & .06 & -.01 & .05 & .11 & .03 & .06 \\ \text { Expectation to enjoy } & .13 & .10 & .05 & .14 & .18^{*} & .16 & .13\end{array}$

the interaction

Ratings After Bogus Information and Before Interaction

\begin{tabular}{|c|c|c|c|c|c|c|c|c|}
\hline How eager to interact & .01 & .12 & -.02 & .08 & .09 & .01 & .08 & .06 \\
\hline $\begin{array}{l}\text { Expectation to enjoy } \\
\text { the interaction }\end{array}$ & .01 & .13 & -.03 & .03 & .04 & -.04 & .10 & .02 \\
\hline Expectation of liking & .12 & -.01 & .10 & .14 & .07 & .07 & .13 & 14 \\
\hline
\end{tabular}

$$
\text { for the other }
$$

${ }^{*} p<.05,{ }^{* *} p<.01,{ }^{* * *} p<.001$ 
index of liking was positively associated with their partner's index of liking $\left(r_{\text {partial }}=.20, p<.05\right)$. Second, perceived reciprocity in liking was even higher. Controlling for similarity condition, the more that participants liked their partner, the more they believed that their partner liked them in return $(r$ partial $=.58, p<.001)$. However, participants were generally not accurate in estimating how much they were liked. Controlling for similarity condition, one participant's liking for their conversational partner was not associated with their partner's estimation of being liked ( $\left.r_{\text {partial }}=.13, p=.148\right)$. In sum, there was both actual and perceived reciprocity in liking, but the participants were not good judges of how much they were liked.

Do high pre-interaction expectations have negative effects on post-interaction liking? Above, it was reported that participants' pre-interaction expectations were associated positively with their post-interaction reactions. Here, it is considered whether there may be a nonlinear association as well. To examine this, an index of pre-interaction expectations was created from the five items that assessed expectations (two from the preliminary survey and three from the brief survey completed after the receipt of bogus information; $\alpha=.90$ ). When degree of post-interaction liking was regressed on this index of expectations, both a linear $\left(R^{2}=.094, F=13.45\right.$, $p<.001)$ and a quadratic effect $\left(R^{2}=.118, F=8.65\right.$, $p<.001)$ were found. The quadratic effect was such that, as speculated, a higher degree of expectations was associated with a slight downturn in post-interaction liking for the other (see Figure in Supplementary File).

\section{Discussion}

In the study of first impressions and initial liking, much more research has been conducted that involves participants responding to a static photo or description of another (who often is bogus) than involves actual first interactions and data collected from both members (Eastwick et al., 2019). This is due in part to the logistical and methodological challenges of conducting such studies. Nonetheless, such social interaction or "getting-acquainted" studies have been conducted, particularly since the creation of fast-friends procedures (Aron et al., 1997; Sedikides et al., 1999) that were designed to develop temporary closeness in the laboratory. The major purpose of this study was to examine how pre-interaction expectations of members of zero-history dyads are associated with their later reactions after a structured get-acquainted interaction. Two items on expectations (about enjoying the interaction and looking forward to it) were included in an initial online survey that the participants completed after the first manipulation of the study (the presence or absence of an initial Skype greeting). Expectation items were then asked again (including the item on expectations about liking the other) in an online survey administered after the second manipulation (bogus information on similarity vs. dissimilarity information).

The findings on the effects of the pre-interaction manipulation of similarity links this study to a long-standing line of research on the role of similarity in early attraction. Prior research (e.g., Byrne, 1971), including by this author (Sprecher, 2019), has examined how bogus information about a target's bogus similarity affects (expectations for) liking and other affiliative outcomes. In most of the original studies that examined the effects of similarity in an experimental context, the "other" did not exist (i.e., was phantom) and, furthermore, in most cases, the participants were not even falsely given the expectation that they would meet the other person. Similar to those early studies, this study found that that receiving (bogus) similarity information about a target person led to greater (expectations of) liking the other than receiving dissimilarity information about the other.

A unique contribution of this study for the literature on the effects of similarity on attraction was the examination of whether having a visual greeting prior to receiving the bogus information reduced the effect of the bogus information on liking and the other affiliative outcomes. It could be speculated that the presence of the other (through the initial Skype greeting) would make the similarity (or dissimilarity) information less salient. However, this was not found to be the case. The results of this study indicated that the effect of the similarity-dissimilarity information on expectations was not moderated by the whether the dyad had a greeting before receiving the information. Furthermore, the main effect of the Skype greeting was also not significant for initial expectations.

Another way that this study extended prior research using the typical phantom-other design is that it examined whether the pre-interaction (bogus) similarity information continued to have an effect on reactions after interaction. Many years ago, communication scholars were instrumental in examining the role of actual communication as a moderator of the effect of similarity on attraction. In a seminal study, Sunnafrank and Miller (1981) used the bogus stranger method within a communication context. They first asked participants to respond to a stranger based on ostensible responses to a survey. Similar to prior bogus-similarity studies (Byrne, 1971), they found a positive effect of the manipulation of similarity on initial attraction. Some of the dyads were then randomly assigned to interact for $5 \mathrm{~min}$ to become acquainted. The researchers found no difference in attraction (assessed after the interaction) as a function of the pre-interaction manipulation of similarity. According to Sunnafrank (1983), initial conversations are likely to lead to "increased impressions of stability, predictability, and controllability in the case of dissimilar strangers" (p. 277) and thus there should be equal degrees of attraction to a stranger after a first interaction regardless of preinteraction information on similarity. That is, new information 
acquired about the other should override any prior dissimilarity information (see also, Sunnafrank, 1984, 1985, 1992). Extending the research by Sunnafrank and others, the current study also found that the pre-interaction manipulation of similarity did not affect post-interaction liking for the other or other affiliative outcomes (closeness, enjoyment of interaction, and perception of being liked). However, the dyad members continued to perceive greater similarity (post-interaction) in the similarity condition than in the dissimilarity condition.

Although the participants' pre-interaction assessments reflected on average that they expected to have a positive interaction (to enjoy the interaction and to like the other), there was variation in their expectations. A unique contribution of this study was the focus on how these pre-interaction expectations were associated with post-interaction reactions. It was found that people who expected to like the other (and enjoy the interaction) actually did like the other and enjoy the interaction to a greater degree than did those who had lower preinteraction expectations. It is perhaps not surprising that preinteraction expectations were associated positively with later actual reactions. The type of person who would have positive expectations before an interaction are likely to be optimistic and warm in the interaction. Although the correlations between the participants' own expectations and their later reactions were positive (and significant), the correlations were more in the magnitude of weak to moderate (rather than in the strong range). In addition, in ancillary analyses, it was determined that not only was a linear association found between pre-interaction expectations and later liking for the other, but there was also evidence for a nonlinear (quadratic) association, whereby there was a downturn in postinteraction liking when pre-interaction expectations were extremely high.

Although one's own expectations prior to an interaction are associated with one's own reactions after the interaction, the participants' pre-interaction expectations were generally not found to be related to their partner's reactions. Thus, while there may be a self-fulfilling prophecy in response to one's own expectations for feelings, they do not affect the partner's reactions over the course of a 15-min getting-acquainted interaction.

\section{Strengths and Limitations of the Study}

While there have been many studies that have examined how people react to descriptions of a bogus person without having any interaction with that person, much less common are studies that involve getting-acquainted dyads actually interacting and providing responses to measures both pre- and post-interaction. The design of such a study allows for examination of issues that would otherwise not be possible. This study focused on how pre-interaction expectations were associated with later reactions, not only obtained from the participants themselves, but also from their partner. This study also had the strength of extending prior literature on the role of preinteraction similarity (vs. dissimilarity) information on initial attraction by examining: (a) whether the effect was moderated by an initial visual greeting (no prior study has done this); and (b) adding to the small literature on whether the effects of preinteraction similarity information on initial reactions extend to affect post-interaction outcomes.

One limitation of this study - in its focus on the role of preinteraction expectations in the get-acquainted process - is that expectations cannot be manipulated (although for an exception, see Aron et al., 1997, referred to earlier). Thus, while this study found that participants' pre-interaction associations were associated positively with their own reactions to the interaction, expectations cannot be disentangled from individual difference variables, such as general optimism, extroversion, and rejection sensitivity, which may affect both expectations and reactions after the interaction. Another limitation is that the interaction lasted only $15 \mathrm{~min}$ and was in one session. It would be interesting to examine how initial expectations change over time with new information. The study also had the limitation that it consisted of a majority of femalefemale dyads, and did not focus on romantic attraction in getting-acquainted dyads. Furthermore, future research could consider how individual difference variables (including gender and race/ethnicity) - as well as how the dyad members may differ on these characteristics - influence the expectations formed as well as the outcomes of those expectations.

\section{Implications, Applications, and Conclusions}

Often people today have first interactions through more than one modality, and also acquire digital information about each other during the early stage of first impressions. For example, people may meet briefly for the first time in a public setting and have a very brief interaction not too different from the Skype greeting in this study. Then they may learn more information about each other through the Internet such as through social media or even profile information provided at Internet dating sites - not too different from the bogus information that was provided to the participants in this study. Furthermore, and amplified during the COVID pandemic of 2020, people are often having their first meaningful and disclosive interactions through video-mediated communication (e.g., Skype or Zoom), as indicated by anecdotal evidence (Basu, 2020; Williams, 2020). Therefore, the findings of this study have implications for how people are developing new relationships and friendships.

More specifically, one important implication is that an initial (brief) visual greeting - although likely making the other person salient - may not reduce the effects of any digital information acquired that could lead to inferences about similarity/dissimilarity on expectations formed. People expect 
to like the other and enjoy the interaction more when they learn they have similar (vs. dissimilar) interests, traits, and preferences with the other, regardless of whether they had an initial video-mediated greeting. On the other hand, a second important implication is that if people get to the stage of a meaningful first interaction, any preliminary information obtained digitally (such as the degree to which they are similar) may not affect reactions after the interaction. A third implication of the results is that if people enter a getting-acquainted interaction with optimistic expectations - and as long as these expectations are not too extraordinarily high - they are likely to have positive reactions in the interaction. And, finally, another implication of the results is that it is possible to have an intimate, meaningful getting-acquainted interaction over visual-mediated communication (e.g., Skype) leading to positive outcomes.

These findings also contribute to the small but growing literature on the relationship functioning and well-being during the COVID pandemic (e.g., Nabity-Grover, Cheung, \& Thatcher, 2020; Riva, Mantovani, \& Wiederhold, 2020; Tanhan \& Strack, 2020). In addition, the findings can have practical implications for counselors of adolescents and young adults, who may need advice on the importance of their own expectations to facilitate the formation of relationships.

Supplementary Information The online version contains supplementary material available at https://doi.org/10.1007/s12144-021-01466-4.

Acknowledgments The author would like to thank all of the following students who worked in the author's research lab during a semester in which data were collected on this project: Chantell Anderson, Victoria Andriulis, Omi Bartov (lab director, Michel Carter (lab director), Becky Cottrell, Diana Davellis, Taylor Genseal (lab director), Lisa Lodesky, Cristian Lucas, Alicia Ramos (lab director), Katie Ruehle, Amanda Steinbach, Elizabeth Sulikowski, Seth Thomas.

Data Availability The data analyzed for the current study are available from the corresponding author on reasonable request.

\section{Declarations}

Conflict of Interest The author states that there is no conflict of interest.

\section{References}

Altman, I., \& Taylor, D. A. (1973). Social penetration: The development of interpersonal relationships. New York: Holt, Rinehart \& Winston.

Antheunis, M. L., Schouten, A. P., Valkenburg, P. M., \& Peter, J. (2012). Interactive uncertainty reduction strategies and verbal affection in computer-mediated communication. Communication Research, 39, 757-780. https://doi.org/10.1177/2F0093650211410420.
Aron, A., Aron, E. N., \& Smollan, D. (1992). Inclusion of other in the self scale and the structure of interpersonal closeness. Journal of Personality and Social Psychology, 63, 596-612 https://psycnet. apa.org/doi/10.1037/0022-3514.63.4.596.

Aron, A., Dutton, D. G., Aron, E. N., \& Iverson, A. (1989). Experiences of falling in love. Journal of Social and Personal Relationships, 6 , 243-257. https://doi.org/10.1177/2F0265407589063001.

Aron, A., Melinat, E., Aron, E. N., Vallone, R. D., \& Bator, R. J. (1997). The experimental generation of interpersonal closeness: A procedure and some preliminary findings. Personality and Social Psychology Bulletin, 23, 363-377. https://doi.org/10.1177/ 2F0146167297234003.

Aronson, E., \& Worchel, P. (1966). Similarity versus liking as determinants of interpersonal attractiveness. Psychonomic Science, 5, 157158. https://doi.org/10.3758/BF03328329.

Basu, T. (2020). Zoom matchmaking is giving lockdown singletons a shot at love. MIT Technology Review. Available at: https://www. technologyreview.com/2020/05/06/1001189/zoom-bacheloretteonline-matchmaking-coronavirus-lockdown-love-lives/

Baumeister, R. F., \& Leary, M. R. (1995). The need to belong: Desire for interpersonal attachments as a fundamental human motivation. Psychological Bulletin, 117, 497-529. https://doi.org/10.1037/ 0033-2909.117.3.497.

Bayer, J. B., Triệu, P., \& Ellison, N. B. (2020). Social media elements, ecologies, and effects. Annual Review of Psychology, 71, 471-497. https://doi.org/10.1146/annurev-psych-010419-050944.

Berscheid, E., Graziano, W., Monson, T., \& Dermer, M. (1976). Outcome dependency: Attention, attribution, and attraction. Journal of Personality and Social Psychology, 34, 978-989 https://psycnet.apa.org/doi/10.1037/0022-3514.34.5.978.

Berscheid, E., \& Reis, H. T. (1998). Attraction and close relationships. In D. T. Gilbert, S. T. Fiske, \& G. Lindzey (Eds.), The handbook of social psychology (Vol. 2, $4^{\text {th }}$ ed. pp. 193-281). New York: McGraw-hill.

Boothby, E. J., Cooney, G., Sandstrom, G. M., \& Clark, M. S. (2018). The liking gap in conversations: Do people like us more than we think? Psychological Science, 29, 1742-1756. https://doi.org/10. 1177/2F0956797618783714.

Byrne, D. (1971). The attraction paradigm. New York: Academic Press.

Carnegie, D. (1936). How to win friends and influence people. New York: Pocket Books.

Condon, J. W., \& Crano, W. D. (1988). Inferred evaluation and the relation between attitude similarity and interpersonal attraction. Journal of Personality and Social Psychology, 54, 789-797 https://psycnet.apa.org/doi/10.1037/0022-3514.54.5.789.

Curtis, R. C., \& Miller, K. (1986). Believing another likes or dislikes you: Behaviors making the beliefs come true. Journal of Personality and Social Psychology, 51, 284-290 https://psycnet.apa.org/doi/10. 1037/0022-3514.51.2.284

Darley, J. M., \& Berscheid, E. (1967). Increased liking as a result of the anticipation of personal contact. Human Relations, 20, 29-40. https://doi.org/10.1177/2F001872676702000103.

Eastwick, P. W., \& Finkel, E. J. (2009). Reciprocity of liking. In H. T. Reis \& S. Sprecher (Eds.), Encyclopedia of human relationships (pp. 1333-1336). Thousand Oaks: SAGE Publications, Inc.. https://doi.org/10.4135/9781412958479.n433.

Eastwick, P. W., Finkel, E. J., \& Simpson, J. A. (2019). Relationship trajectories: A meta-theoretical framework and theoretical applications. Psychological Inquiry, 30, 1-28. https://doi.org/10.1080/ 1047840X.2019.1577072.

Ellison, N. B., \& Vitak, J. (2015). Social network site affordances and their relationship to social capital processes. In S. Sundar (Ed.), The handbook of the psychology of communication technology (pp. 205227). Hoboken: Wiley-Blackwell. https://doi.org/10.1002/ 9781118426456.ch9. 
Finkel, E. J., \& Eastwick, P. W. (2015). Interpersonal attraction: In search of a theoretical Rosetta stone. In J. A. Simpson \& J. F. Dovidio (Eds.), Handbook of personality and social psychology: Interpersonal relations and group processes (pp. 179-210). Washington, DC: American Psychological Association https:// psycnet.apa.org/doi/10.1037/14344-007.

Fraley, B., \& Aron, A. (2004). The effect of a shared humorous experience on closeness in initial encounters. Personal Relationships, 11, 61-78. https://doi.org/10.1111/j.1475-6811.2004.00071.x.

Gouldner, A. W. (1960). The norm of reciprocity: A preliminary statement. American Sociological Review, 25, 161-178. https://doi.org/ $10.2307 / 2092623$.

Hampton, A. J., Fisher Boyd, A. N., \& Sprecher, S. (2019). You're like me and I like you: Mediators of the similarity-liking link assessed before and after a getting-acquainted social interaction. Journal of Social and Personal Relationships, 36, 2221-2244. https://doi.org/ 10.1177/2F0265407518790411.

Hirsch, J. L., \& Clark, M. S. (2019). Multiple paths to belonging that we should study together. Perspectives on Psychological Science, 14, 238-255. https://doi.org/10.1177/2F1745691618803629.

Holt-Lunstad, J. (2018). Why social relationships are important for physical health: A systems approach to understanding and modifying risk and protection. Annual Review of Psychology, 69, 437-458. https:// doi.org/10.1146/annurev-psych-122216-011902.

Huston, T. L., Caughlin, J. P., Houts, R. M., Smith, S. E., \& George, L. J. (2001). The connubial crucible: Newlywed years as predictors of marital delight, distress, and divorce. Journal of Personality and Social Psychology, 80, 237-252 https://psycnet.apa.org/doi/10. 1037/0022-3514.80.2.237.

LeFebvre, L. E. (2018). Swiping me off my feet: Explicating relationship initiation on tinder. Journal of Social and Personal Relationships, 35, 1205-1229. https://doi.org/10.1177/2F0265407517706419.

Lemay Jr., E. P., \& Wolf, N. R. (2016). Projection of romantic and sexual desire in opposite-sex friendships: How wishful thinking creates a self-fulfilling prophecy. Personality and Social Psychology Bulletin, 42, 864-878. https://doi.org/10.1177/2F0146167216646077.

Montoya, R. M., \& Horton, R. S. (2012). The reciprocity of liking effect. In M. Paludi (Ed.), The psychology of love (pp. 39-57). Santa Barbara: Praeger https://psycnet.apa.org/record/2012-08260-017.

Montoya, R. M., \& Horton, R. S. (2013). A meta-analytic investigation of the processes underlying the similarity-attraction effect. Journal of Social and Personal Relationships, 30, 64-94. https://doi.org/10. 1177/2F0265407512452989.

Montoya, R. M., Horton, R. S., \& Kirchner, J. (2008). Is actual similarity necessary for attraction? A meta-analysis of actual and perceived similarity. Journal of Social and Personal Relationships, 25, 889922. https://doi.org/10.1177/2F0265407508096700.

Montoya, R. M., \& Insko, C. A. (2008). Toward a more complete understanding of the reciprocity of liking effect. European Journal of Social Psychology, 38, 477-498. https://doi.org/10.1002/ejsp. 431.

Montoya, R. M., Kershaw, C., \& Prosser, J. L. (2018). A meta-analytic investigation of the relation between interpersonal attraction and enacted behavior. Psychological Bulletin, 144, 673-709 https:// psycnet.apa.org/doi/10.1037/bul0000148.

Nabity-Grover, T., Cheung, C. M., \& Thatcher, J. B. (2020). Inside out and outside in: How the COVID-19 pandemic affects self-disclosure on social media. International Journal of Information Management, 55, 102188. Downloaded from https://www.sciencedirect.com/ science/article/pii/S0268401220310331?via\%3Dihub. https://doi. org/10.1016/j.ijinfomgt.2020.102188.

Ramirez Jr., A. (2007). The effect of anticipated future interaction and initial impression valance on relational communication in computermediated interaction. Communication Studies, 58, 53-70. https:// doi.org/10.1080/10510970601168699.
Reis, H. T., Maniaci, M. R., Caprariello, P. A., Eastwick, P. W., \& Finkel, E. J. (2011). Familiarity does indeed promote attraction in live interaction. Journal of Personality and Social Psychology, 101, 557570 https://psycnet.apa.org/doi/10.1037/a0022885.

Riva, G., Mantovani, F., \& Wiederhold, B. K. (2020). Positive technology and COVID-19. Cyberpsychology, Behavior and Social Networking, 23, 581-587. https://doi.org/10.1089/cyber.2020. 29194.gri.

Sandstrom, G. M., \& Dunn, E. W. (2014). Social interactions and wellbeing: The surprising power of weak ties. Personality and Social Psychology Bulletin, 40, 910-922. https://doi.org/10.1177/ 2F0146167214529799.

Sedikides, C., Campbell, W. K., Reeder, G. D., \& Elliot, A. J. (1999). The relationship closeness induction task. Representative Research in Social Psychology, 23, 1-4.

Sharabi, L. L. (2020). Online dating profiles, first-date interactions, and the enhancement of communication satisfaction and desire for future interaction. Communication Monographs, 1-23. https://doi.org/10. 1080/03637751.2020.1766094.

Sharabi, L. L., \& Caughlin, J. P. (2017). What predicts first date success? A longitudinal study of modality switching in online dating. Personal Relationships, 24, 370-391. https://doi.org/10.1111/pere. 12188.

Snyder, M., Tanke, E. D., \& Berscheid, E. (1977). Social perception and interpersonal behavior: On the self-fulfilling nature of social stereotypes. Journal of Personality and Social Psychology, 35, 656-666 https://psycnet.apa.org/doi/10.1037/0022-3514.35.9.656.

Sprecher, S. (1998). Insiders' perspectives on reasons for attraction to a close other. Social Psychology Quarterly, 61, 287-300 https://www. jstor.org/stable/2787031.

Sprecher, S. (2019). Does dis (similarity) information about a new acquaintance lead to liking or repulsion? An experimental test of a classic social psychology issue. Social Psychology Quarterly, 18, 303-318. https://doi.org/10.1177/2F0190272519855954.

Sprecher, S., \& Treger, S. (2015). The benefits of turn-taking reciprocal self-disclosure in get-acquainted interactions. Personal Relationships, 22, 460-475. https://doi.org/10.1111/pere.12090.

Stinson, D. A., Cameron, J. J., Wood, J. V., Gaucher, D., \& Holmes, J. G. (2009). Deconstructing the "reign of error": Interpersonal warmth explains the self-fulfilling prophecy of anticipated acceptance. Personality and Social Psychology Bulletin, 35, 1165-1178. https://doi.org/10.1177/2F0146167209338629.

Sunnafrank, M. (1983). Attitude similarity and interpersonal attraction in communication processes: In pursuit of an ephemeral influence. Communications Monographs, 50, 273-284. https://doi.org/10. 1080/03637758309390170.

Sunnafrank, M. (1984). A communication-based perspective on attitude similarity and interpersonal attraction in early acquaintance. Communication Monographs, 51, 372-380. https://doi.org/10. 1080/03637758409390208.

Sunnafrank, M. (1985). Attitude similarity and interpersonal attraction during early communicative relationships: A research note on the generalizability of findings to opposite-sex relationships. The Western Journal of Speech Communication, 49, 73-80. https://doi. org/10.1080/10570318509374182.

Sunnafrank, M. (1986). Predicted outcome value during initial interactions: A reformulation of uncertainty reduction theory. Human Communication Research, 13, 3-33. https://doi.org/10.1111/j. 1468-2958.1986.tb00092.x.

Sunnafrank, M. (1992). On debunking the attitude similarity myth. Communication Monographs, 59, 164-179. https://doi.org/10. 1080/03637759209376259.

Sunnafrank, M. J., \& Miller, G. R. (1981). The role of initial conversations in determining attraction to similar and dissimilar strangers. Human Communication Research, 8, 16-25. https://doi.org/10. 1111/j.1468-2958.1981.tb00653.x. 
Tanhan, A., \& Strack, R. W. (2020). Online photovoice to explore and advocate for Muslim biopsychosocial spiritual wellbeing and issues: Ecological systems theory and ally development. Current Psychology, 39, 2010-2025. https://doi.org/10.1007/s12144-02000692-6.

Tyler, T. R., \& Sears, D. O. (1977). Coming to like obnoxious people when we must live with them. Journal of Personality and Social Psychology, 35, 200-2011 https://psycnet.apa.org/doi/10.1037/ 0022-3514.35.4.200.

Vittengl, J. R., \& Holt, C. S. (2000). Getting acquainted: The relationship of self-disclosure and social attraction to positive affect. Journal of Social and Personal Relationships, 17, 53-66. https://doi.org/10. 1177/2F0265407500171003.

Walther, J. B. (1992). Interpersonal effects in computer-mediated interaction: A relational perspective. Communication Research, 19, 52 90. https://doi.org/10.1177/2F009365092019001003.
Walther, J. B. (1996). Computer-mediated communication: Impersonal, interpersonal, and hyperpersonal interaction. Communication Research, 23, 3-43. https://doi.org/10.1177/ 2F009365096023001001.

Williams, A. (2020). College students are still finding romance in a pandemic, through zoom crushes and actual dates. The Washington Post. Available at: https://www.washingtonpost.com/lifestyle/ 2020/10/13/college-dating-relationships-pandemic/

Zimmermann, J., Schindler, S., Klaus, G., \& Leising, D. (2018). The effect of dislike on accuracy and bias in person perception. Social Psychological and Personality Science, 9, 80-88. https://doi.org/10. 1177/2F1948550617703167.

Publisher's Note Springer Nature remains neutral with regard to jurisdictional claims in published maps and institutional affiliations. 